\title{
Styl jako praktyka i forma pamięci zbiorowej
}

\author{
Marta Wójcicka \\ Uniwersytet Marii Curie-Skłodowskiej w Lublinie \\ marta.wojcicka@poczta.umcs.lublin.pl
}

\begin{abstract}
Streszczenie
Przedmiotem artykulu sa relacje między stylem językowym a pamięcia zbiorowa. Styl, ujmowany semiotycznie i antropologicznie, stanowi jedna z form pamięci zbiorowej, obok typu tekstu kultury, odmiany, a także gatunku tekstu. Styl jest wyrazem, świadectwem przeszłości. Ze stylu indywidualnego, np. uznanych pisarzy, odczytać można ich obraz rzeczywistości, w tym także przeszłości. Styl jest więc nośnikiem zarówno pamięci indywidualnej danego pisarza, jak też świadectwem przeszłości, $w$ której żyt i tworzyt. Style typowe stanowia lustro odzwierciedlajace właściwe dla danej epoki konwencje wyrażania. Styl przechowuje więc obraz przeszłości, indywidualnej i zbiorowej, jest środkiem dotarcia do niej oraz sposobem wyrażania przeszłości oraz mówienia o przeszłości $i$ jej niewerbalnych nośnikach wspótcześnie. Styl funkcjonalny ukazano więc jako praktykę oraz formę pamięci zbiorowej: komunikatywnej lub kulturowej. Styl potoczny stanowi praktyke wcielania, podczas gdy pozostałe style funkcjonalne sa praktykami zapisu. Pamięć komunikatywna przekazywana jest przez środki $i$ wartości typowe dla stylu potocznego, pamięć kulturowa związana jest praktycznie ze wszystkimi stylami funkcjonalnymi, w zależności od treści pamięci.
\end{abstract}

Stowa kluczowe: styl: indywidualny, typowy, funkcjonalny, pamięć zbiorowa: komunikatywna, kulturowa

Abstract

Style as a practice and a form of collective memory

The subject of the article are relations between a language style and collective memory. The style, semiotically and anthropologically presented, is one of the forms of collective memory along with a type of culture text, variety and text genre as well. On the one hand, the style is an expression, evidence of the past. From an individual style of e.g. recognized writers one can interpret their image of reality, including also the past. Thus the style is a means of conveying both individual memory of a particular author and evidence of the past he used to live in and create. Typical styles are the mirrors reflecting conventions of expression appropriate for a given period. Thus, the style stores the image of the past, individual and collective, and is a means of reaching it, a way of expressing and talking about it, including its contemporary 
nonverbal means. Thus, a functional style has been presented as practice and the form of collective memory: communicative or cultural. A colloquial style is the practice of incorporating, whereas other functional styles are practices of recording. Communicative memory is conveyed by means and values typical for the colloquial style, while cultural memory is practically associated with all functional styles, depending on the contents of memory.

\section{Wstęp}

Pamięć zbiorowa, definiowana jako „element komunikacji kulturowej, zawarty w tekstach kultury zbiór wyobrażeń członków zbiorowości o jej przeszłości” (Wójcicka 2015: 68), wyraża się w języku. Język jest determinantą pamięci oraz jej nośnikiem, modelem i interpretatorem (zob. Wójcicka 2017). Istotnym dla funkcjonowania, przekazywania, a także konstruowania pamięci zbiorowej jest zatem styl, rozumiany antropologicznie, jako „całokształt zachowań językowych człowieka uwarunkowanych podmiotowo, pragmatycznie, kognitywnie i kulturowo" (Gajda 2013: 7). Celem artykułu jest zatem wskazanie relacji między pamięcią zbiorową a stylem językowym. Styl traktowany jest jako medium pamięci, stanowiące wyraz pamięci komunikatywnej i kulturowej oraz świadectwo pamięci użycia. ${ }^{1}$ Podstawę materiałową i materiał egzemplifikacyjny stanowią wypowiedzi ludzi (znanych i anonimowych), które są wspomnieniami na temat stanu wojennego w Polsce.

\section{Styl funkcjonalny - medium czy nośnik pamięci?}

Pamięć zbiorowa, czyli obraz przeszłości, jest przechowywana i przekazywana za pośrednictwem mediów i nośników pamięci.

Nośniki pamięci definiuję jako makroznaki, materialne, idealne lub zdarzeniowe teksty kultury, które niosą informację o obrazie przeszłości danej grupy społecznej, będącej autorem lub depozytariuszem pamięci utrwalonej w danym tekście. Nośniki zawierają pewne gotowe wizje przeszłości. Można więc postawić pytanie: co pamięta dany nośnik? Jaki obraz przeszłości zawarty jest w tekście kultury-nośniku pamięci.

Media pamięci „nie pełnią jedynie funkcji przekaźników „gotowych pamięci”, lecz same W sobie stają się treścią przekazu, czyli ,aktorami”, tworząc dyskursywne ramy, dostarczając lub narzucając style i formuły opowiadania o przeszłości czy kreując i promując określone figury pamięci” (Pakier, Saryusz-Wolska 2014: 214). Media pamięci mają wymiar czasowy. Stanowią one środki (łac. medius = środkowy), które uczestniczą w przekazywaniu 
obrazu pamięci. Dzięki mediom pamięci tekst kultury, uczestnicząc w komunikacji kulturowej, wpływa na przemiany pamięci zbiorowej i samej kultury. Analiza mediów pamięci pozwala odpowiedzieć na pytanie: jak dany tekst kultury funkcjonuje w pamięci zbiorowej? Jak zmienia się jego obieg (odbiór, przekaz, transformacje, parafrazy itp.) i jak wpływa to na zmianę obrazu przeszłości? Takie ujęcie mediów pamięci wydaje się bliskie koncepcji Astrid Erll, według której „media pamięci nie są neutralnymi nośnikami treści zawierających pewne wizje przeszłości, lecz same konstytuują te wizje, wraz z uniwersum wartości i norm oraz koncepcji tożsamości, które się w nich zawierają. Obrazy przeszłości nie istnieją niezależnie od mediów - są konstruktami wytwarzanymi przez media pamięci” (Pakier, Saryusz-Wolska 2014: 214). Media pamięci biorą więc udział w wytwarzaniu nośników pamięci, które przekazują obraz przeszłości. Przykład może stanowić ciało, które bierze udział w wytwarzaniu nośników pamięci: tekstów ustnych, pisanych, obrzędów itp., czasem stając się także jednym z jego elementów (np. obrzędów).

A zatem, nośnik pamięci to znak, natomiast media pamięci to środki wytwarzające znaki, które mogą też stanowić ich części składowe. ${ }^{2}$

Styl sam w sobie nie stanowi więc nośnika pamięci. Jest jednak nieuchronnie związany z pamięcią zbiorową. Jak zauważyła Astrid Erll, media pamięci, do których zaliczam styl komunikacyjny, wraz z wartościami i normami konstytuują zawarte w tekstach kultury nośnikach pamięci - wizje przeszłości. W stylu bowiem zawarte jest wartościowanie przeszłości, jej wytworów i zawartego w nich obrazu świata, czego egzemplifikację stanowi następująca opowieść Krystyny Prońko:

12 grudnia graliśmy „Kolędę nockę” w Teatrze Muzycznym w Gdyni. Dojeżdżający wykonawcy mieszkali w Grand Hotelu w Sopocie. W nocy obudził mnie telefon od Haliny Frąckowiak, żebym wyjrzała przez okno. Na ulicy stały jakieś kordony. Chwilę później zapukano do moich drzwi. Mundurowy milicjant zażądał dowodu osobistego, a jeden z dwóch ubranych w moro ludzi zajrzał pod łóżko, do szafy i łazienki, ale nie za zasłony, co mnie zdziwiło. Kiedy wyszli usłyszałam dobiegające zewsząd stukoty i szuranie mebli. Domyśliłam się, że wyłuskiwano delegatów Krajowej Komisji „Solidarności”, których m.in. kwaterowano także w Grand Hotelu. Rankiem na śniadaniu w restauracji spotkali się tylko artyści i przerażeni kelnerzy. Telefony nie działały, pojechałyśmy więc z Haliną do teatru, bo w niedzielę miałyśmy znów występować. Trwał poranek dla dzieci, ale nasze wieczorne przedstawienia już się nie odbyły. Wracałyśmy okazją - mercedesem, który wpadł w poślizg i otarł się o słup. Pociąg do Warszawy był już po godzinie milicyjnej, więc bałyśmy się, że zostaniemy zaaresztowane $\mathrm{w}$ drodze na peron. Dojechałyśmy jednak bez przeszkód, choć kontrolowano nam nie tylko bilety, ale i dokumenty. Cierpiał też mój pies, któremu godzina milicyjna wyeliminowała późne wieczorne spacery. 
(http://culture.pl/pl/artykul/wprowadzenie-stanu-wojennego-we-wspomnieniach-ludzi-kultury z dn. 25.07.2017)

„Styl ma wobec tekstu charakter transgresyjny” (Witosz 2009: 38), ,jest ponadtekstową strukturą znakową" (Bartmiński 1981: 31). Uogólniając można powiedzieć, że media pamięci mają więc wobec nośników charakter transgresyjny oraz stanowią ich immanentną cechę.

Relacje styl-pamięć zbiorowa pokazać można, odwołując się do - wskazanych przez Stanisława Gajdę - podstawowych założeń teorii stylu.

1) Styl, który łączony jest z ludzkim działaniem, także komunikacyjno-językowym w określonym kontekście społeczno-kulturowym (Gajda 2013: 26), jest świadectwem patrzenia na przeszlość i środkiem kreowania obrazów przeszłości, które zawsze związane są z wartościami i aktualnymi potrzebami grupy społecznej - nosiciela pamięci zbiorowej. Jako przykłady posłużą wspomnienia $\mathrm{z}$ okresu stanu wojennego: jedno opisane $\mathrm{W}$ stylu anegdotycznym, z dystansem i przymrużeniem oka (Jerzy Urban), dwa kolejne - autorstwa anonimowych internautów - pierwsze - opisane w stylu sprawozdawczym, konkretne, pozbawione wyrazów nacechowanych, a przez to jeszcze bardziej dramatyczne, drugie - także krótkie, relacyjno-wspomnieniowe, ukazujące przeplatanie się życia rodzinnego ze społecznym:

W stanie wojennym mój zięć, który pracował w konspiracji jako drukarz, powziął z kolegami plan. Marzyło im się zabicie generała Jaruzelskiego. Planowali wysadzić w powietrze jego dom wraz z lokatorem. Zamyślali detonować w nocy bombę umieszczoną w rurach kanalizacyjnych. Wiedzieli tylko mniej więcej, gdzie mieszka Generał, ale nie potrafili zidentyfikować domu. Przyjęli więc, że siedzibą „dyktatora” jest najokazalsza rezydencja otoczona murem. Gdyby zrealizowali przedsięwzięcie, wyleciałby w powietrze ambasador USA. I byłby niezły pasztet. Zięć opisał to w swojej książce - wspomnieniach o konspirze. W latach 90. miałem okazję przedstawić Generałowi jego niedoszłego zabójcę. Potraktował go z ciepłym humorem i oczarował, co umiał. (http://jerzyurban.blog.pl/tag/stan-wojenny/ z dn. 25.07.2016).

13 grudnia 1981 mój brat był w wojsku, a mnie zabrało pogotowie do porodu i 14 grudnia o 9 rano urodziłam syna, który zawodowo pracuje w Marynarce Wojennej na Oksywiu. WIDZ (http://www.tvp.info/9419588/wasze-wspomnienia-z-13-grudnia-1981-r z dn. 25.07.2016)

13 grudnia to dzień urodzin mojego syna. W 1981 roku kończył akurat 5 lat. W dniu ogłoszenia stanu wojennego, nie rozumiejący powagi sytuacji syn powiedział: „No nie, mamo, nie mogli tego stanu ogłosić jutro, tylko akurat dzisiaj w moje urodziny?” Każdego roku, dwa wielkie wydarzenia 
stanowią jedno. Grażyna B. (http://www.tvp.info/9419588/wasze-wspomnienia-z-13-grudnia1981-r z dn. 25.07.2016)

Zdaniem Jerzego Bartmińskiego, styl jest „ponadtekstową strukturą znakową, w której stroną znaczoną (signifié) są uporządkowane w pewien sposób wartości, a stroną znaczącą (signifiant), czyli eksponentami tych wartości, są elementy języka przynależne do różnych poziomów jego struktury" (Bartmiński 1981: 32). Wartości stylu odpowiadają za proces selektywności pamięci zbiorowej. Wskazywane przez Jerzego Bartmińskiego wartości stylu, czyli założenia ontologiczne dotyczące świata i człowieka, typ racjonalności, punkt widzenia generujący określony obraz świata oraz intencjonalność komunikowania (Bartmiński 1991: 13), decydują o pamiętaniu lub zapominaniu, a także o sposobie kreowania i interpretowania przeszłości. I tak jak „kategorią integrującą zarówno wartości stylu, jak i ich tekstowe komponenty jest podmiot wypowiedzi" (Witosz 2009: 39), tak podmiot integruje też styl i pamięć zbiorową, bowiem ,pamięci zbiorowych jest wiele, tyle ile grup, które budując swą tożsamość, odwołują się do przeszłości. Fragmenty przeszłości zachowane we wspomnieniach stanowią część jej wyobrażeń o sobie samej. Z tego też powodu pamięć zbiorowa zmienia się wraz z systemem wartości respektowanym w danej grupie lub zbiorowości” (Szpociński 2006: 28).

Zarazem styl rozumiany jako zachowanie językowe ujmować można jako praktykę pamięci zbiorowej, w zależności od stylu - praktykę wcielania lub zapisu. ${ }^{3}$ Jak pisał Paul Connerton, „nie ma praktyk bez podtrzymujących je nośników, ani też nośników bez ożywiających je praktyk" (Napiórkowski 2012: 12). Nośnikiem pamięci, jak wspomniano na początku, jest $\mathrm{m}$. in. tekst (ustny bądź też pisany), styl jest wynikiem praktyk wcielania lub zapisu.

W praktykę wcielania zaangażowane jest ludzkie ciało. Działanie komunikacyjnojęzykowe, w którym uczestniczy ciało, związane jest przede wszystkim ze stylem potocznym oraz odmianą ustną ${ }^{4}$, dlatego traktować je można jako przykłady praktyki wcielania. Praktyki zapisu Paul Connerton wiąże $\mathrm{z}$ nowoczesnymi urządzeniami do przechowywania i odzyskiwania informacji: drukiem, fotografią, kasetą magnetofonową, komputerem „wszystkie one wymagają, byśmy zrobili coś, co uwięzi i zatrzyma informację jeszcze długo po tym, jak ludzki organizm zakończy proces komunikacji” (Connerton [1989] 2012: 191). Z praktyką zapisu związane są więc pozostałe style funkcjonalne, przede wszystkim artystyczny i artystyczny ludowy, ale też naukowy, urzędowy $\mathrm{i}$ in. oraz odmiana pisana. 
2) „JA i społeczność [...] to istotny element każdej koncepcji stylu” (Gajda 2013: 26). JA i społeczność to także istotni nosiciele pamięci, bo - mimo że pamięć ma jedynie jednostka, to ,jednostka dojrzewająca w zupełnej samotności nie posiadałaby pamięci. Pamięć rozwija się w człowieku wraz z procesem jego socjalizacji. Co prawda tylko jednostki „mają” pamięć, ale jest ona ukształtowana przez zbiorowość. [...] Zbiorowości nie „mają” pamięci, ale kształtują pamięć swoim członków” (Assmann [1992] 2008: 52).

Styl jest świadectwem obecności społeczności w JA, to jest pamięci zbiorowej w przekazie jednostkowym, w tym także - tak jak w poniższym przykładzie obrazów medialnych, wypowiedzi innych ludzi:

Gdy ogłoszono stan wojenny miałam 11 lat. Rano nie było bajki co było dla mnie dziwne, bo zawsze była. Pokazali gen. Jaruzelskiego. Po jego wystąpieniu mama powiedziała wtedy coś strasznego: „w tym roku śnieg będzie czerwony”. Potem widziałam pociągi, którymi - pod plandekami - przywożono czołgi. Widziałam gąsienice. Jechały, jak się potem dowiedziałam, do kopalni w Jastrzębiu Zdroju. Byłam też kontrolowana przez trzech zomowców, czy nie noszę ulotek. Nigdy tak się nie bałam... miałam wtedy tylko 11 lat. RENATA (http://www.tvp.info/9419588/wasze-wspomnienia-z-13-grudnia-1981-r z dn. 25.07.2016)

3) Podstawą współdziałania ludzi są teksty jako dynamiczne i otwarte całości treściowo-pragmatyczno-semiotyczne (Gajda 2013: 26). Teksty, jak już wspomniano, są nośnikami pamięci zbiorowej, stanowią centrum działań komunikacyjnych i pamięci zbiorowej.

4) Styl przenika tekst, stanowi jego „duszę" (Gajda 2013: 26), a tekst, głównie tekst ustny jest prototypowym nośnikiem pamięci, także nośnikiem pamięci o stylu danej epoki. „Pamięć zbiorowa zależy od przekazu ustnego w stopniu zmiennym w różnych przypadkach, ale na ogół pokaźnym. Jakoż to, co przedstawiają obrazy, pozostaje niezrozumiałe bez otoczki słownej, która ustanawia stosunki między postaciami i scenami a opowieściami i wierzeniami” (Pomian 2006: 150). Styl potoczny, głównie w odmianie ustnej, stanowi więc nie tylko „centrum systemu stylowego języka” (Bartmiński 2001: 116), ale też „centrum” pamięci zbiorowej. Styl potoczny dominuje nad pozostałymi: jest przyswajany jako pierwszy w procesie akwizycji języka, jest używany najczęściej, przez największą liczbę osób, w najróżniejszych sytuacjach życiowych. Przede wszystkim styl potoczny utrwala „elementarne struktury myślenia i percepcji świata związane z elementarnymi potrzebami człowieka w elementarnych sytuacjach egzystencjalnych. Styl potoczny pełni rolę bazy derywacyjnej dla pozostałych stylów językowych, tzn. wszystkie pozostałe w jakiś sposób pochodzą od potocznego, ale także rolę tła, na którym funkcjonują style wyspecjalizowane i wobec którego 
określają swoiste dla siebie właściwości. Bez niego nie udaje się wyodrębnić i opisać innych stylów językowych” (Bartmiński 2001: 117). Tak jak bez stylu potocznego nie da się opisać innych stylów, tak bez niego nie da się przekazać treści pamięci zbiorowej. Może być ona co prawda przenoszona także za pomocą niewerbalnych, głównie materialnych, nośników pamięci, np. pomników, fotografii, które jednak pozbawione tzw. ucieleśnienia - w postaci towarzyszących im tekstów ustnych - stają się pustymi semantycznie artefaktami, nośnikami niepamięci zbiorowej. Ta definiowana jest jako „bezpowrotna i całkowita utrata wiedzy o określonych fragmentach minionej rzeczywistości, lecz także odnosi się do treści, które zostały zachowane za pomocą różnych metod utrwalania przeszłości” (Kwiatkowski 2014: 273). Teksty kultury rozumiane jako wytwory praktyk zapisu, np. pomniki, fotografie, obrazy, utrwalają przeszłość, ale pozbawione społecznej narracji są raczej śladem przeszłości (zob. Wójcicka 2015c). Podkreśla to także Wojciech Chlebda, pisząc: „Gdy więc utrzymuję, że pamięć sama w sobie - jej psychiczna zawartość - jest naszemu poznaniu niedostępna, chcę powiedzieć, że badanie pamięci jest możliwe o tyle, o ile jest badaniem języka, jakiego użyto po to, by treść pamięci uzewnętrznić, a jest skuteczne w takiej mierze, w jakiej uwzględniamy fakt, że werbalizacja może nieść z sobą (i niesie nieuchronnie) także skróty, konwencjonalizację, stereotypizację i im podobne deformacje treści wyjściowych" (Chlebda 2012: 115). Przykład swego rodzaju konwencjonalizacji i stereotypizacji stanowią wypowiedzi internautów wspominających stan wojenny. W większości wspomnień osób, które wówczas miały po kilka/kilkanaście lat, pojawia się ten sam wątek - poranek bez Teleranka:

Miałem dziewięć i niedzielny poranek bez teleranka a przed kościołem wojsko czołgi i ZOMO. PIOTR B. (http://www.tvp.info/9419588/wasze-wspomnienia-z-13-grudnia-1981-r $\quad \mathrm{z} \quad \mathrm{dn}$. $25.07 .2016)$

Mialam wtedy 14 lat! Dla mnie ta niedziela to nie tylko brak ,Teleranka”, to paniczny strach! Ze wspomnień ludzi wiedziałam co było w 70r. Dziś zapalę świece! Małgorzata J. (http://www.tvp.info/9419588/wasze-wspomnienia-z-13-grudnia-1981-r z dn. 25.07.2016)

Ponieważ centrum nie tylko systemu stylowego, ale i pamięciowego, stanowi - jak już wspomniano - styl potoczny w odmianie ustnej, to parafrazując myśl W. Chlebdy, można powiedzieć, że badanie pamięci zbiorowej jest możliwe o tyle, o ile jest badaniem stylu potocznego w odmianie ustnej, stanowiącego budulec werbalnego tekstu kultury - ten może być nośnikiem pamięci lub jej interpretantem (w znaczeniu semiotycznym ${ }^{5}$ ), wskazującym na 
znaczenie niewerbalnego znaku - nośnika pamięci.

Jednocześnie cechy i właściwości stylu, tak indywidualnego, jak i konkretnego i funkcjonalnego obecnych $\mathrm{w}$ danym czasie, są przechowywane $\mathrm{w}$ pamięci zbiorowej za pośrednictwem tekstu. Styl jest więc także treścią (czy też przedmiotem) pamięci zbiorowej.

\section{Pamięć zbiorowa a styl indywidualny i typowy}

Z kategorią pamięci związany jest zarówno styl (konkretnego) tekstu, jak również styl indywidualny $\mathrm{i}$ typowy. Ten pierwszy charakteryzowany jest jako „odnoszony do niepowtarzalnego, konkretnego tekstu” (Gajda 2013: 27). Tekst, przekazywany w procesie komunikacji społecznej, staje się nośnikiem pamięci o danym czasie, „lustrem odbijającym epokę", a styl tekstu stanowi medium tejże pamięci. Jednocześnie sam tekst i styl stanowią, jak już wspomniano, treść pamięci, i w całości są przekazywane z pokolenia na pokolenie.

Styl indywidualny (idiostyl) łączy się z osobowością jednostki. Jest to „sposób, w jaki konkretny autor wyraża w tekstach swoje widzenie świata”, jest to także „właściwość społeczno-komunikacyjnej kompetencji [jednostki] lub wyraz tożsamości, którą jednostka wytwarza sobie dyskursywnie w świecie, w którym żyje w różnych sytuacjach życiowych. [...] Styl to dyskursywny aspekt tożsamości” (Gajda 2013: 27). Styl indywidualny uczestniczy więc w kształtowaniu i przekazywaniu treści pamięci indywidualnej. Mimo, że „podmiotem pamięci i pamiętania pozostaje dla nas pojedynczy człowiek”, to ,jest on zależny od „ram” organizujących pamięć” (Assmann [1992] 2008: 53). Tak jak pamięć indywidualna jest zależna od zbiorowej, tak też styl indywidualny, zawierając w sobie „to, co inwentywne i to, co wspólne, ogólne” (Gajda 2013: 27), jest też środkiem przekazywania nie tylko pamięci jednostkowej, ale i zbiorowej. Przykład stylu indywidualnego, poetyckiego patrzenia na wydarzenia stanu wojennego, a także swoistej uniwersalizacji tamtych wydarzeń stanowi wypowiedź Jacka Kaczmarskiego:

„Uważam, że stan wojenny trwa - dla każdego - przez całe życie, od narodzin do śmierci. Zawsze istnieją nowe wyzwania, zawsze jest konieczność wyboru: pomiędzy aktywnością i biernością, buntem i posłuszeństwem, myśleniem i jedzeniem. I dlatego kiedyś śpiewaliśmy o niewoli, teraz - o tym, co zrobić z wolnością" - mówił po latach Jacek Kaczmarski w jednym ze swoich wywiadów dla „Gazety Wyborczej”. (https://histmag.org/Jacek-Kaczmarski-poetycka-pamiec-ostanie-wojennym-784 z dn. 25.07.2016)

Styl typowy charakteryzowany jest jako „schematyczny sposób realizacji intencji 
komunikacyjnych związany z sytuacjami komunikacyjnymi, epokami historycznymi, prądami literackimi, gatunkami wypowiedzi” (Zdunkiewicz-Jedynak 2008: 19). Styl typowy jest więc świadectwem danej epoki, typowego dla określonego czasu sposobu wyrażania. W rejestrze stylów typowych wymieniane są m. in. mówiony i pisany, oficjalny i nieoficjalny, style gatunkowe, funkcjonalne, narodowe, generacyjne i epok, męski i żeński i in. (zob. Gajda 2013: 27) Zarówno odmiany mówiona i pisana, jak i style funkcjonalne, czyli „społecznie uświadamiane, wewnętrznie scalone i funkcjonalnie uwarunkowane zespoły środków językowych" (Gajda 2013: 28), związane są ze wspomnianymi wcześniej praktykami pamięci: wcielania i zapisu i odnieść je można do typów pamięci zbiorowej: komunikatywnej i kulturowej, o czym w dalszej części artykułu.

\section{Typologia stylów a rodzaje pamięci zbiorowej}

Styl jako środek pamięci zbiorowej, działanie komunikacyjno-językowe odnieść można do zaproponowanej przez Jana Assmanna typologii, ponieważ pamięć „,żyje w komunikacji i dzięki niej” (Assmann [1992] 2008: 52).

Tabela 1. Styl jako jedno z kryterium typologii pamięci zbiorowej (opracowanie: Marta Wójcicka)

\begin{tabular}{|c|c|c|c|}
\hline & Pamięć komunikatywna & Pamięć kulturowa & $\pi$ \\
\hline Treść & $\begin{array}{l}\text { doświadczanie historii w ramach } \\
\text { biografii indywidualnej }\end{array}$ & $\begin{array}{l}\text { mityczna prehistoria, wydarzenia } \\
\text { z przeszłości absolutnej }\end{array}$ & ח. \\
\hline Formy & $\begin{array}{l}\text { nieformalne, mało wykształcone, } \\
\text { naturalne, powstające przez } \\
\text { powszednie interakcje }\end{array}$ & $\begin{array}{l}\text { ufundowane, kunsztowne, } \\
\text { komunikacja ceremonialna, } \\
\text { święto }\end{array}$ & 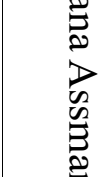 \\
\hline Media & $\begin{array}{l}\text { żywe wspomnienia w } \\
\text { jednostkowej pamięci, } \\
\text { doświadczeniu i przekazie }\end{array}$ & $\begin{array}{l}\text { trwałe obiektywacje, tradycyjne i } \\
\text { symboliczne } \\
\text { kodowanie/inscenizowanie przez } \\
\text { słowo, obraz, taniec etc. }\end{array}$ & 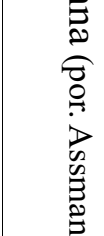 \\
\hline $\begin{array}{l}\text { Struktura } \\
\text { czasowa }\end{array}$ & $\begin{array}{l}\text { 80-100 lat, horyzont } 3-4 \text { pokoleń } \\
\text { przesuwający się } \quad \text { wraz } \quad \text { z } \\
\text { teraźniejszością }\end{array}$ & $\begin{array}{l}\text { absolutna przeszłość mitycznego } \\
\text { praczasu }\end{array}$ & 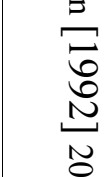 \\
\hline Nosiciele & $\begin{array}{l}\text { niewyspecjalizowani, } \\
\text { świadkowie wspólnoty pamięci }\end{array}$ & $\begin{array}{l}\text { wyspecjalizowani } \quad \text { nosiciele } \\
\text { tradycji }\end{array}$ & U \\
\hline Odbiorcy & świadkowie wydarzeń, aktywni & nieskonkretyzowani, bierni & $0 \pi$ \\
\hline
\end{tabular}




\begin{tabular}{|c|l|l|}
\hline \hline $\begin{array}{c}\text { Sytuacja } \\
\text { komunikacyjna }\end{array}$ & $\begin{array}{l}\text { role nadawcy i odbiorcy } \\
\text { wymienne }\end{array}$ & $\begin{array}{l}\text { role nadawcy i odbiorcy wyraźnie } \\
\text { przypisane do określonych typów } \\
\text { osób }\end{array}$ \\
\hline Zasięg & lokalny & Ponadlokalny \\
\hline $\begin{array}{c}\text { Praktyki } \\
\text { pamięci }\end{array}$ & wcielania & wcielania i zapisu \\
\hline $\begin{array}{c}\text { Typ } \\
\text { tekstu } \\
\text { kultury }\end{array}$ & tekst ustny & $\begin{array}{l}\text { tekst werbalny (ustny lub pisany), } \\
\text { tekst niewerbalny (np. fotografia, } \\
\text { pomnik), } \\
\text { tekst werbalno-niewerbalny (np. } \\
\text { obrzęd, film) }\end{array}$ \\
\hline $\begin{array}{c}\text { Styl } \\
\text { funkcjonalny } \\
\text { tekstu }\end{array}$ & potoczny & Potoczny \\
& artystyczny \\
& artystyczny ludowy \\
& & naukowy \\
Odmiana & Mówiona & urzędowy \\
\hline
\end{tabular}

Zaprezentowana powyżej tabela ukazuje dwa typy pamięci: komunikatywną i kulturową. Rozróżnione są one przez Jana Assmanna na podstawie pięciu kryteriów. Są to: treść, formy, media, struktura czasowa i nosiciele. Do tych podstawowych kryteriów, na podstawie badań tekstów ustnych, można dodać kolejne, tj. odbiorcy, sytuacja komunikacyjna, zasięg, praktyki pamięci, typy tekstów kultury, styl funkcjonalny i odmiana.

Pamięć zbiorowa, jak podkreślał Jan Assmann, żyje w komunikacji, a więc biorą w niej udział uczestnicy pełniący role nadawcy i odbiorcy. W kontekście teorii pamięci nadawca jest nosicielem pamięci, ale rola odbiorcy wcale nie jest lub nie musi być bierna. W pamięci komunikatywnej role te są wymienne, co sprzyja procesowi transmisji wewnątrz i międzypokoleniowej, przekazywaniu pamięci. Nośnikiem pamięci komunikatywnej jest więc 
przede wszystkim tekst ustny, a jego immanentną cechą oraz medium pamięci zbiorowej stanowi styl potoczny w odmianie mówionej. Jego wartości: konkretność, antropocentryzm, zdroworozsądkowość decydują o tym, co z przeszłości grupy społecznej, będącej depozytariuszem pamięci, ma być pamiętane, a co zapominane. Pamiętane jest bowiem to, co potrzebne, istotne z punktu widzenia grupy, aktualne.

Pamięć kulturowa przekazywana jest w różnych werbalnych, bądź też niewerbalnych tekstach kultury. Jeśli skupimy się wyłącznie na tekstach werbalnych - ustnych lub pisanych które dominują w przekazywaniu treści pamięci zbiorowej, stanowiąc np. składnik tekstu (podpisy pod fotografiami, tytuły dzieł sztuki, teksty wypowiadane w filmie lub przedstawieniu teatralnym itp.), to pamięć kulturowa przekazywana jest we wszystkich stylach językowych w odmianie ustnej lub pisanej. Jak już jednak wspomniano, styl potoczny w odmianie ustnej stanowi tu podstawowy interpretant tekstu kultury-nośnika pamięci, niezależnie od jego formy.

\section{Wnioski}

Związki stylu językowego z pamięcią zbiorową, mimo że są bardzo ścisłe, to nie są oczywiste. Styl językowy jest świadectwem patrzenia na przeszłość i środkiem kreowania obrazów przeszłości, które zawsze związane są z wartościami i aktualnymi potrzebami grupy społecznej - nosiciela pamięci zbiorowej. Jednocześnie, styl jest świadectwem obecności społeczności w JA, to jest pamięci zbiorowej w przekazie jednostkowym.

Styl językowy stanowi medium pamięci zbiorowej, bierze udział w wytwarzaniu i przekazywaniu nośników pamięci - tekstów kultury. W stylu zawarte jest wartościowanie przeszłości, jej wytworów i zawartego w nich obrazu świata. Styl rozumiany jako zachowanie językowe ujmować można jako praktykę pamięci zbiorowej. Wynikiem praktyki wcielania jest styl potoczny i odmiana mówiona, skutkiem praktyki zapisu są pozostałe style funkcjonalne i odmiana pisana.

$\mathrm{Na}$ cele działania stylów funkcjonalnych należy spojrzeć w kontekście tworzenia i przekazywania obrazów przeszłości, w tym także w kontekście typów pamięci zbiorowej. Medium pamięci komunikatywnej stanowi styl potoczny w odmianie mówionej. Jego wartości: konkretność, antropocentryzm, zdroworozsądkowość decydują o tym, co z przeszłości grupy społecznej, będącej depozytariuszem pamięci, ma być pamiętane, a co zapominane. Pamięć 
kulturowa przekazywana jest we wszystkich stylach językowych w odmianie ustnej lub pisanej Styl zawiera więc obraz przeszłości, konstytuuje nośniki pamięci zbiorowej, bierze udział w przekazywaniu pamięci komunikatywnej i kulturowej.

\section{Przypisy}

${ }^{1}$ Do materialnych nośników pamięci można zaliczyć fotografię, obraz, film, pomnik. Idealne nośniki pamięci to nazwy, teksty ustne i pisane. Zdarzeniowe nośniki pamięci stanowią obrzędy, obchody, rekonstrukcje, pochody.

${ }^{2}$ Więcej o mediach i nośnikach pamięci w: Wójcicka (2015c).

${ }^{3}$ Przykładem praktyk pamięci jest także stylizacja, zob. Wójcicka (w druku 2).

${ }^{4}$ Przyjmuję rozróżnienie między odmianą i stylem, stosowane przez Jerzego Bartmińskiego (1981), według którego „różnica między odmianą a stylem tkwi w płaszczyźnie semiotycznej. Style, za którymi stoją wybory wartości, postaw poznawczych, relacji do odbiorcy itp. nie są wzajemnie zastępowalne. Ta cecha przysługuje odmianom, np. mówionej i pisanej”.

${ }^{5}$ Tekst w stylu potocznym (ustnym) można potraktować jako tzw. znak, który odnosząc się do innego znaku (np. fotografii), staje się interpretantem zewnętrznym, który „czyni ze znaku środek przekazu, inaczej komunikacji” i „stanowi jakiś praktyczny rezultat oddziaływania znakowego w procesie komunikacji” (Żegleń 2000: 46).

\section{Bibliografia}

Assmann, Jan ([1992] 2008) Pamięć kulturowa. Pismo, zapamiętywanie i polityczna tożsamość w cywilizacjach starożytnych. [Das kulturelle Gedächtnis. Schrift, Erinnerung und politische Identität in frühen Hochkulturen. München: C.H. Beck] (tłum.) Anna Kryczyńska-Pham, Robert Traba (red.). Warszawa: Wydawnictwo UW.

Bartmiński, Jerzy (1981) „Derywacja stylu”. [W:] Jerzy Bartmiński (red.) Pojęcie derywacji w lingwistyce. Lublin: Wydawnictwo UMCS; 31-54.

Bartmiński, Jerzy (1991) „Styl potoczny jako centrum systemu stylowego języka”. [W:] Stanisław Gajda (red.) Synteza w stylistyce słowiańskiej. Opole: Wydawnictwo WSP; 33-47.

Bartmiński, Jerzy (2001) „Styl potoczny”. [W:] Jerzy Bartmiński (red.) Współczesny język polski. Lublin: Wydawnictwo UMCS; 115-134.

Chlebda, Wojciech (2012) „Pamięć ujęzykowiona”. [W:] Jan Adamowski, Marta Wójcicka (red.) Tradycja dla współczesności, t. 6: Pamięć jako kategoria rzeczywistości kulturowej. Lublin: Wydawnictwo UMCS; 109-119. 
Connerton, Paul ([1989] 2012) Jak społeczeństwa pamiętaja [How Societies Remember. Cambridge: Cambridge University Press] (tłum.) Marcin Napiórkowski. Warszawa: Wydawnictwo Uniwersytetu Warszawskiego.

Gajda, Stanisław (2013) „Teoria stylu i stylistyka”. [W:] Ewa Malinowska, Jolanta Nocoń, Urszula Żydek-Bednarczuk (red.) Style współczesnej polszczyzny. Przewodnik po stylistyce polskiej. Kraków: Wydawnictwo Universitas; 15-34.

Kwiatkowski, Piotr T. (2014) „Niepamięć”. [W:] Magdalena Saryusz-Wolska, Robert Traba, (red.) Modi memorandi. Leksykon kultury pamięci. Warszawa: Wydawnictwo Naukowe Scholar; 272-274.

Napiórkowski, Marcin (2012) „Jak społeczeństwa pamiętaja Paula Connertona na tle współczesnych badań nad pamięcią zbiorową". [W:] Paul Connerton, Jak społeczeństwa pamiętaja [How Societies Remember. Cambridge: Cambridge University Press] (thum.) Marcin Napiórkowski. Warszawa: Wydawnictwo Uniwersytetu Warszawskiego; 7-27.

Pakier, Magdalena, Magdalena Saryusz-Wolska (2014) „Media pamięci”. [W:] Magdalena Saryusz-Wolska, Robert Traba (red.) Modi memorandi. Leksykon kultury pamięci. Warszawa: Wyd. Naukowe Scholar; 213-215.

Szpociński, Andrzej (2006) „Formy przeszłości a komunikacja społeczna”. [W:] Andrzej Szpociński, Piotr T. Kwiatkowski, Przeszłość jako przedmiot przekazu. Warszawa: Wydawnictwo Naukowe Scholar; 7-65.

Witosz, Bożena (2009) Dyskurs i stylistyka. Katowice: Wydawnictwo Uniwersytetu Śląskiego.

Wójcicka, Marta (2014) Pamięć zbiorowa a tekst ustny. Lublin: Wydawnictwo UMCS.

Wójcicka, Marta (2015a) „Parafraza tekstu folkloru w świetle teorii pamięci zbiorowej - od pamięci komunikatywnej do międzykulturowej”. [W:] Stanisława NiebrzegowskaBartmińska, Marta Nowosad-Bakalarczyk, Tomasz Piekot (red.) Działania na tekście. Przekład - redagowanie - ilustrowanie. Lublin: Wydawnictwo UMCS; 183-196.

Wójcicka, Marta (2015b) „Wartości a pamięć zbiorowa”. [W:] Jan Adamowski, Marta Wójcicka (red.) Tradycja dla współczesności, t. 8: Wartości w języku i kulturze. Lublin: Wydawnictwo UMCS; 65-72. 
Wójcicka, Marta (2015c) „Media i nośniki pamięci zbiorowej w praktykach wcielania i zapisu”. [W:] Paweł Czajkowski, Barbara Pabjan, Marcelina Zuber (red.) Forum Socjologiczne, t. 6: Pamięć a przestrzeń. Wrocław: Wydawnictwo Uniwersytetu Wrocławskiego; 299-315.

Wójcicka, Marta (w druku 1) „Język pamięci zbiorowej (w kontekście kultury oralności, piśmienności i elektralności). Prolegomena”. [W:] Waldemar Czachur (red.) Lingwistyka pamięci. Warszawa: Wydawnictwo Uniwersytetu Warszawskiego.

Wójcicka, Marta (w druku 2) „Parafraza tekstu folkloru jako praktyka pamięci zbiorowej (czyli Kapturek zmodyfikowany)”. [W:] Ksiega jubileuszowa prof. K. Michajłowej.

Zdunkiewicz-Jedynak, Dorota (2008) Wykłady ze stylistyki. Warszawa: Państwowe Wydawnictwo Naukowe.

Żegleń, Urszula. M. (2000) Wprowadzenie do semiotyki teoretycznej i semiotyki kultury. Toruń: Wyd. Uniwersytetu Mikołaja Kopernika. 